IRA-International Journal of Technology \& Engineering

ISSN 2455-4480; Vol.09, Issue 03 (December 2017)

Pg. no. 16-26

Institute of Research Advances

https://research-advances.org/index.php/IRAJTE

\title{
Application of Particle Image Velocimetry (PIV) for Measuring Water Velocity in Laboratory Sedimentation Tank
}

\author{
King Kuok KUOK ${ }^{1 \#} \&$ Po Chan CHIU ${ }^{2}$ \\ ${ }^{1}$ Faculty of Engineering, Computing and Science, Swinburne University of Technology Sarawak Campus, \\ 93350 Kuching, Sarawak, Malaysia. \\ ${ }^{2}$ Department of Information Science, Faculty of Computer Science and Information Technology, Universiti \\ Malaysia Sarawak, 94300 Kota Samarahan, Sarawak, Malaysia.
}

\#corresponding author.

Type of Review: Peer Reviewed.

DOI: http://dx.doi.org/10.21013/jte.v9.n3.p1

\section{How to cite this paper:}

KUOK, K.K., CHIU, P.C. (2017). Application of Particle Image Velocimetry (PIV) for Measuring Water Velocity in Laboratory Sedimentation Tank. IRA International Journal of Technology \& Engineering (ISSN 2455-4480), 9(3), 16-26. doi:http://dx.doi.org/10.21013/jte.v9.n3.p1

(C) Institute of Research Advances.

\section{(cc) BY-NC}

This work is licensed under a Creative Commons Attribution-Non Commercial 4.0 International License subject to proper citation to the publication source of the work.

Disclaimer: The scholarly papers as reviewed and published by the Institute of Research Advances (IRA) are the views and opinions of their respective authors and are not the views or opinions of the IRA. The IRA disclaims of any harm or loss caused due to the published content to any party.

Institute of Research Advances is an institutional publisher member of Publishers Inter Linking Association Inc. (PILA-CrossRef), USA. The institute is an institutional signatory to the Budapest Open Access Initiative, Hungary advocating the open access of scientific and scholarly knowledge. The Institute is a registered content provider under Open Access Initiative Protocol for Metadata Harvesting (OAI-PMH).

The journal is indexed \& included in WorldCat Discovery Service (USA), CrossRef Metadata Search (USA), WorldCat (USA), OCLC (USA), Open J-Gate (India), EZB (Germany) Scilit (Switzerland), Airiti (China), Bielefeld Academic Search Engine (BASE) of Bielefeld University, Germany, PKP Index of Simon Fraser University, Canada. 


\begin{abstract}
Over the past three decades, Particle Image Velocimetry (PIV), fundamentally based on pattern matching principles, has seen a rapid growth in its usage as a flow measurement technique. PIV is a 'digital' tracking process to measure the time taken for water to move from one point to the other. The particle displacements can be ascertained by measuring the movement of the fluid of interest from the images captured by a camera. In this study, PIV is employed to measure surface flow velocity. The flow velocity was obtained by analyzing the series of captured images using MatPIV codes. The experiment was carried out at Swinburne Sarawak Fluid Lab. Digital SLR camera model used is Nikon D40X which is capable of taking 5 frames per second. Various tracer particles were used for the experiments include food dye, beads and ping pong balls. The experiments were conducted in a SOLTEQ Sedimentation Tank. Through the implementation of a standardized correction factor, the corrected PIV velocity has an error margin less than $5 \%$ which is deemed to be fairly accurate. The PIV velocity $\left(V_{\text {piv }}\right)$ results showed to be in good agreement with the actual velocity $\left(V_{\text {actual }}\right)$.
\end{abstract}

Keywords: Particle Image Velocimetry (PIV), flow velocity, SOLTEQ Sedimentation Tank

\title{
Introduction
}

Traditional measuring water velocity techniques such as current meter and acoustic sensors including Acoustic Doppler Current profilers (ADCP) would require the usage of boats, cable cars or bridges and relevant personnel to wade into the river in order to measure water discharge(Creutin et al., 2003;Harpold et al., 2006). The procedures involved are time consuming, labour intensive and contributing high cost to the river monitoring significantly. Besides, some of the rivers flow velocities in upper catchment of Sarawak are yielding up to $8 \mathrm{~m} / \mathrm{s}$, with the river width of $100 \mathrm{~m}$, and water depth difference for more than $15 \mathrm{~m}$ between low and high flows. It is really risky and endangers the lives of hydrographers to gauge the river flow especially during flood events.

Therefore, this research project intends to apply Particle Image Velocimetry (PIV) for measuring water flow velocity in a SOLTEQ sedimentation tank for creating a relationship between the flow and tracer particles at a laboratory scale.PIV is a field optical measuring technique for fluid velocity which utilized captured optical images to produce instantaneous vector measurements. It is able to measure the displacement of small tracer particles in a fluid by taking two images shortly after one another (Fujitaet al., 1998) using a powerful camera without entering into the river. These recorded images are then processed on a computer using MatPIV to analyze the movement of particles in subsections of the PIV images through cross-correlation techniques. The result would produce a particle-image displacement pattern after taking into consideration of image magnification and time delay. The river flow velocity will be obtained using the two cameras in a stereoscopic arrangement allowing a visualization of a full field three-dimensional visualization (Le Coz et al., 2010; Lowe, 2006). By employing the PIV water measuring technique, the surface flow velocity from any water channel can be easily measured. This will minimize or even eliminate the risks of hydrographers for measuring high speed flow velocity.

There are many advantages in the application of PIV. It is a non-intrusive technique and will not cause significant distortion to the fluid flow. The use of PIV avoids the need of using intrusive flow measurement probes which might affect the quality of measured data. PIV is also capable to measure two dimensional geometry of the flow simultaneously. The process also produces numerous image pairs that can be analyzed at any point of time. Thus, continuous delivery of information can be obtained. Besides, PIV also has a high degree of accuracy yielding up to $10 \%$ of one pixel on the image plane. However, PIV has its limitations too. One of the limitations is the particles might not exactly follow the motion of the fluid due to their immerse density. PIV in general is only able to measure flow inx-axis and y-axis, but not the z-axis. The seeding particles size will also limit the size of the recordable flow field. Another major drawback is the resulting velocity field is only a spatially averaged representation of the actual velocity field. This will reduce the accuracy of the spatial derivatives of the velocity field, vorticity and spatial correlation functions will be affected.

Till to date, Large-Scale particle image velocimetry (LSPIV) technique has been applied at River Arc, France to monitor surface velocities in high flow conditions especially during reservoir release (Jodeau et al., 2008). Besides, LSPIV has also been applied at Ardèche River, Mediterranean to provide velocity and discharge data during flash-floods when conventional methods fail or are difficult to employ (Le Coz et al., 2010). Meanwhile, a study of fish response towards turbulent environments using PIV has been conducted by Pacific Northwest National Library for United States Department of Energy (Deng at al. 2004). 


\section{Methodology}

PIV is falling under the category of Pulsed Light Velocimetry (Sveen \& Cowen, 2004; Adrian, 1991) that uses particulate marker tracers to track fluid displacement. The theory of PIV is derived from the measurement of small tracer particles which is adequately small enough to follow the movement of the fluid of interest. These particles are then illuminated with a thin light sheet. Light scattered from them is then stored in subsequent image frames with known intervals using a camera. By taking two images instantaneously after each another using a high speed camera, PIV measures the whole velocity field and calculates the displacement of particles within the given time frame. Velocity is determined from the measured displacement and time differences. A unique high speed camera is used so that the second image can be immediately taken after the first frame.

In this experiment, the instruments used comprises of the SOLTEQ Sedimentation Tank Model TR 09 (refer to Fig. 1) and the Nikon D40X digital SLR camera. The tracer particles used in this experiment are the 41 orange ping pong balls as shown in Fig. 1a. The ping pong balls have an excellent reflective surface with the ability to scatter light.

PIV process comprises of three main sequences namely acquisition, pixelization and interrogation as illustrated in Fig. 2. In image acquisition, small tracer particles were used to follow the fluid flow. Two laser pulses were fired in rapid succession, separated by a known time $(\Delta \mathrm{t})$. Light is scattered from the tracer particles during each laser pulse. Separate images of scattered light were collected by an optimized PIV camera. The images will be transferred to the computer for processing.
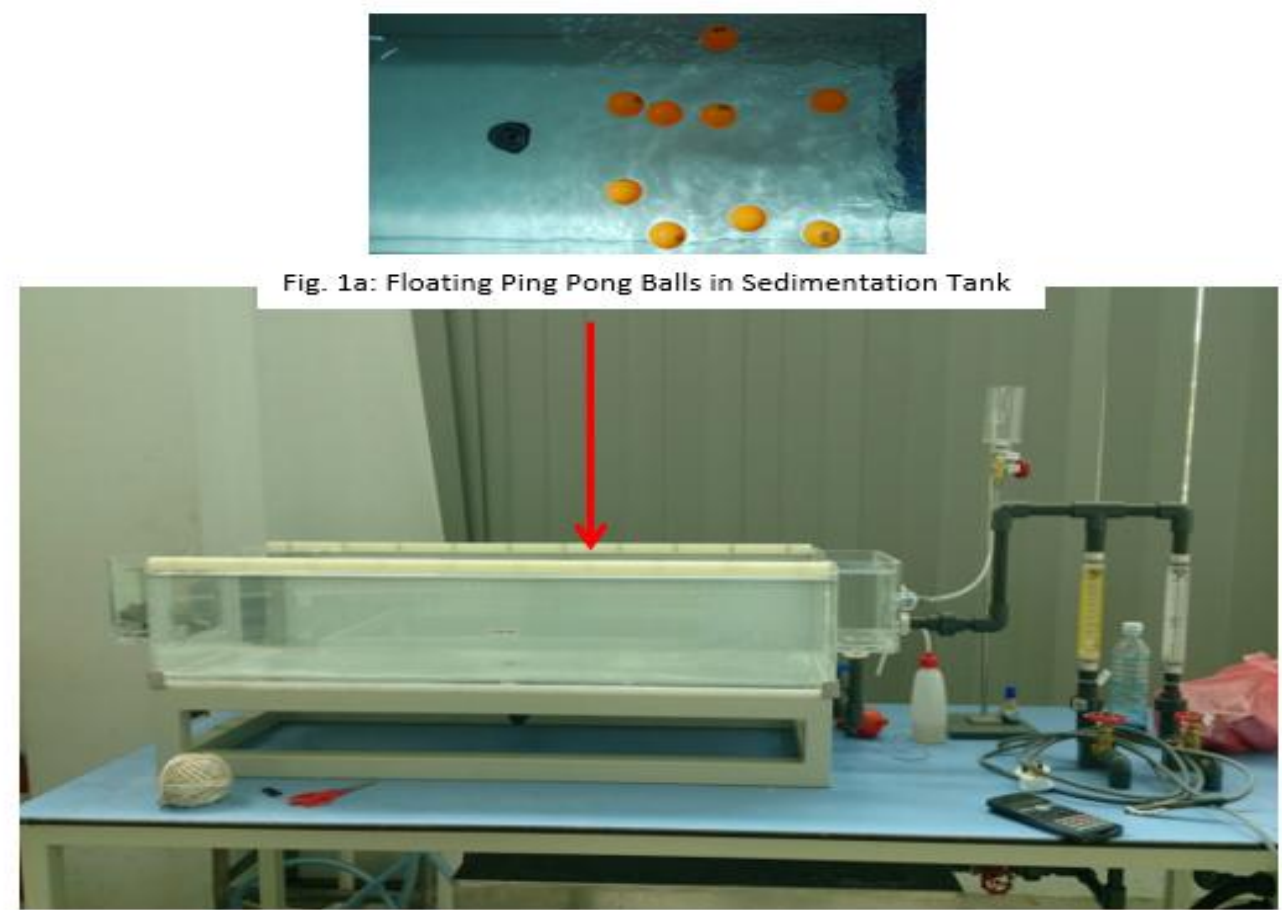

Fig. 1: SOLTEQ Sedimentation Tank Model TR 09

In pixelization, the images obtained were sorted out and rearranged in sequence. Any blur or unsuitable images will be discarded. Based on the distance marking on the equipment, the selected images were scaled to fit the size of open flow channel. The images were then processed through MatPIV to perform image interrogation. Through MatPIV, images were subdivided into many "interrogation windows" where the particle displacements between the two laser pulses were determined though spatial cross-correlation. The process was repeated to produce instantaneous planar velocity field.

The results obtained through MatPIV were validated and analyzed with concurrent measurements through manual calculations. Velocity was determined by dividing the particle displacements with time frame between pulses. Grid lines were plotted in the images to determine the coordinates of ping pong balls. The time between each frame is 0.2 second and 5 frames will be captured within 1 second. 


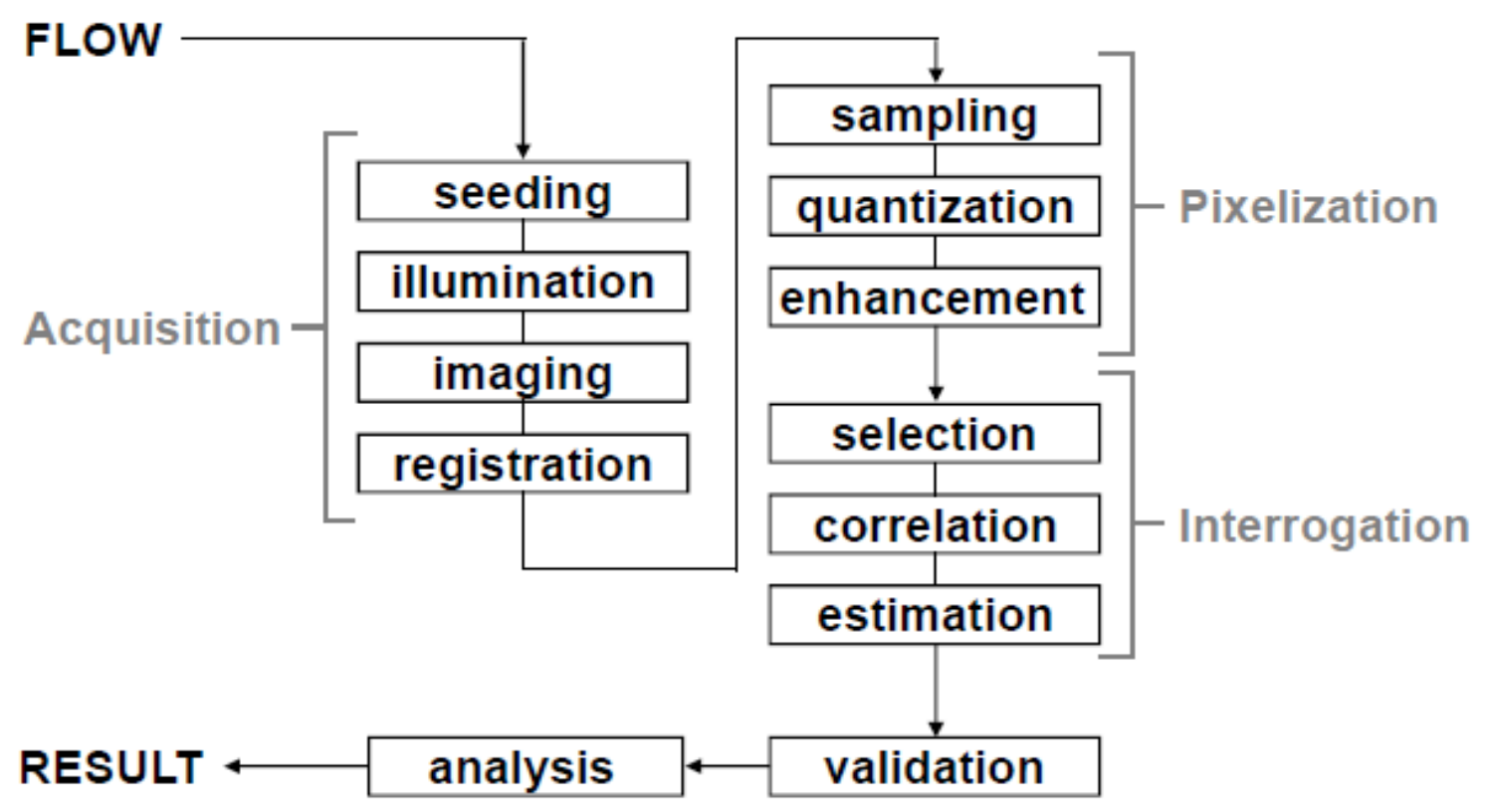

Fig 2: PIV Process Chart

\section{Results and Discussions}

Images acquired were calibrated and scaled into pixel size of $60 \mathrm{cmX}$ by $38 \mathrm{~cm}$. Grid lines with intervals of $4 \mathrm{~cm}$ were drawn on each captured image for determining the coordinates of each ping pong ball. MatPIV is able to present the results of flow velocity and vorticity in different colours. MatPIV will cross correlated the images in pair to generate the velocities both in $\mathrm{x}$ and $\mathrm{y}$ directions. The flow velocity can be determined by calculating the displacement of the ping pong balls between two image frames. In this study, the flow velocity is determined by calculating the ping pong balls displacement in $\mathrm{x}$ direction only. However, the result accuracies might be slightly affected as the size of each ping pong ball is about $4 \mathrm{~cm}$ diameter. MatPIV analysis results shows that the velocity values are positive when the tracer particles travel from left to right and vice versa.

Image frames 1 and 2 (presented in Fig. 3 and Fig. 4) will be input into MatPIV for analysis. MatPIV will justify and calculate the displacement of the ping pong balls between frame 1 and 2. Thereafter, MatPIV will calculate velocities vectors by dividing total displacement with time interval for capturing image frame 1 and frame 2.The velocity vectors obtained is presented in Fig.5 and velocity values in Fig.6a and Fig. 6b.Thereafter, MatPIV will further analyze the velocities vectors between frame 2 and frame 3 (shown in Fig. 7), frame 3 and frame 4 (presented in Fig. 10), frame 4 and frame 5 (presented in Figure 13). Velocity vectors obtained for frame 2 and frame 3 is presented in Fig.8 and the velocity values are shown in Fig. 9a and Fig. 9b. Velocity vectors for frame 3and frame 4 are presented in Fig. 11 and the velocity values in Fig. 12a and Fig 12b. Fig. 14 presents the velocity vector for frame 4 and frame 5, and its velocity values Fig. 15a and Fig. 15b. 


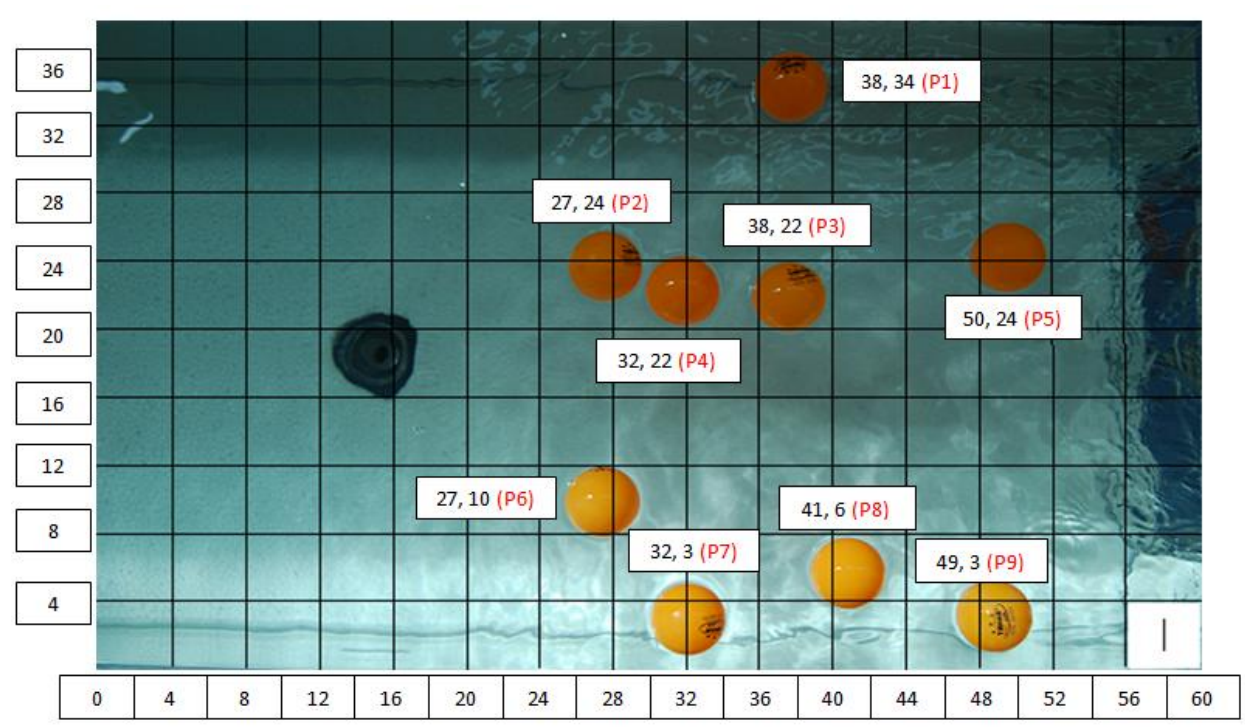

Fig. 3: Image Frame 1 with Ping Pong Ball IDs and Coordinates

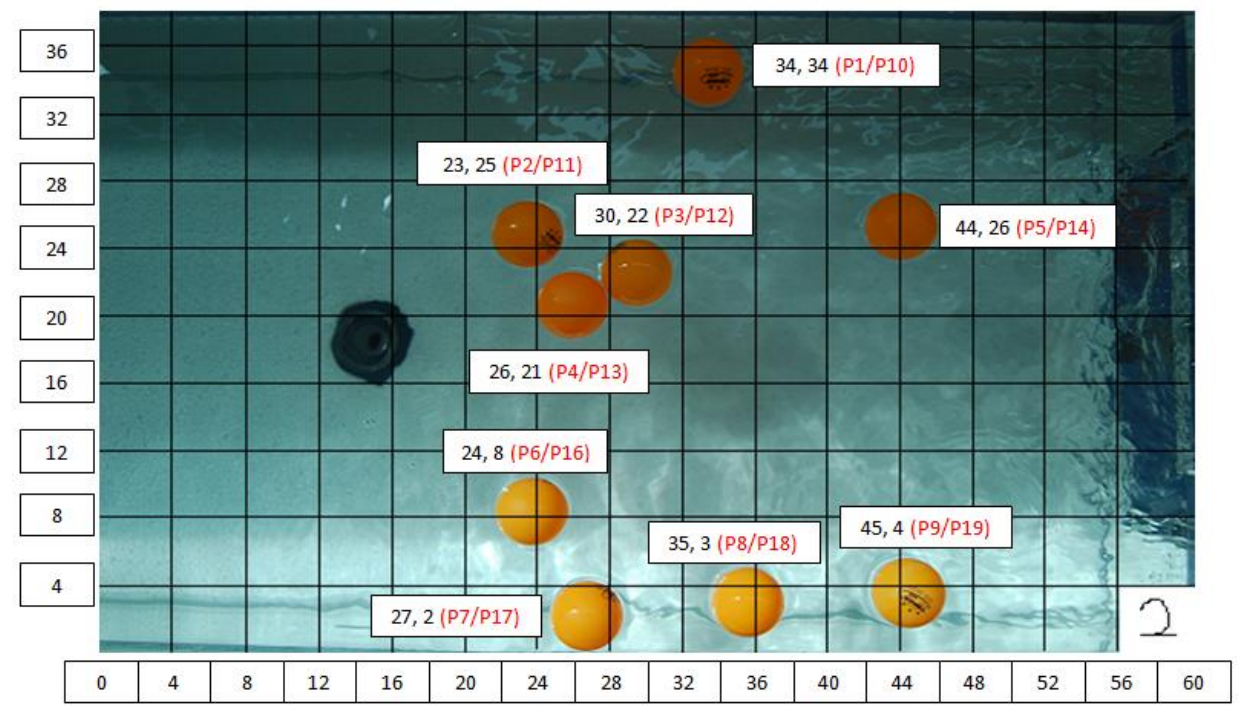

Fig.4: Image Frame 2 with Ping Pong Ball IDs and Coordinates

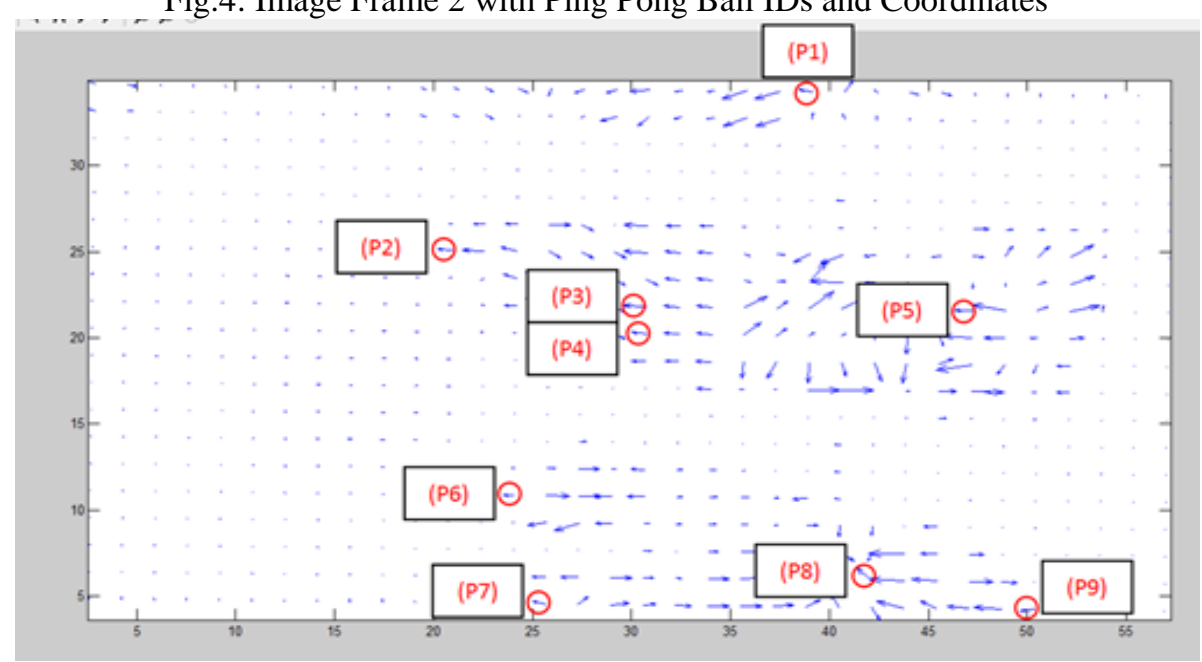

Fig. 5: Velocity Vectors Generated for Fig. 3\& Fig. 4 


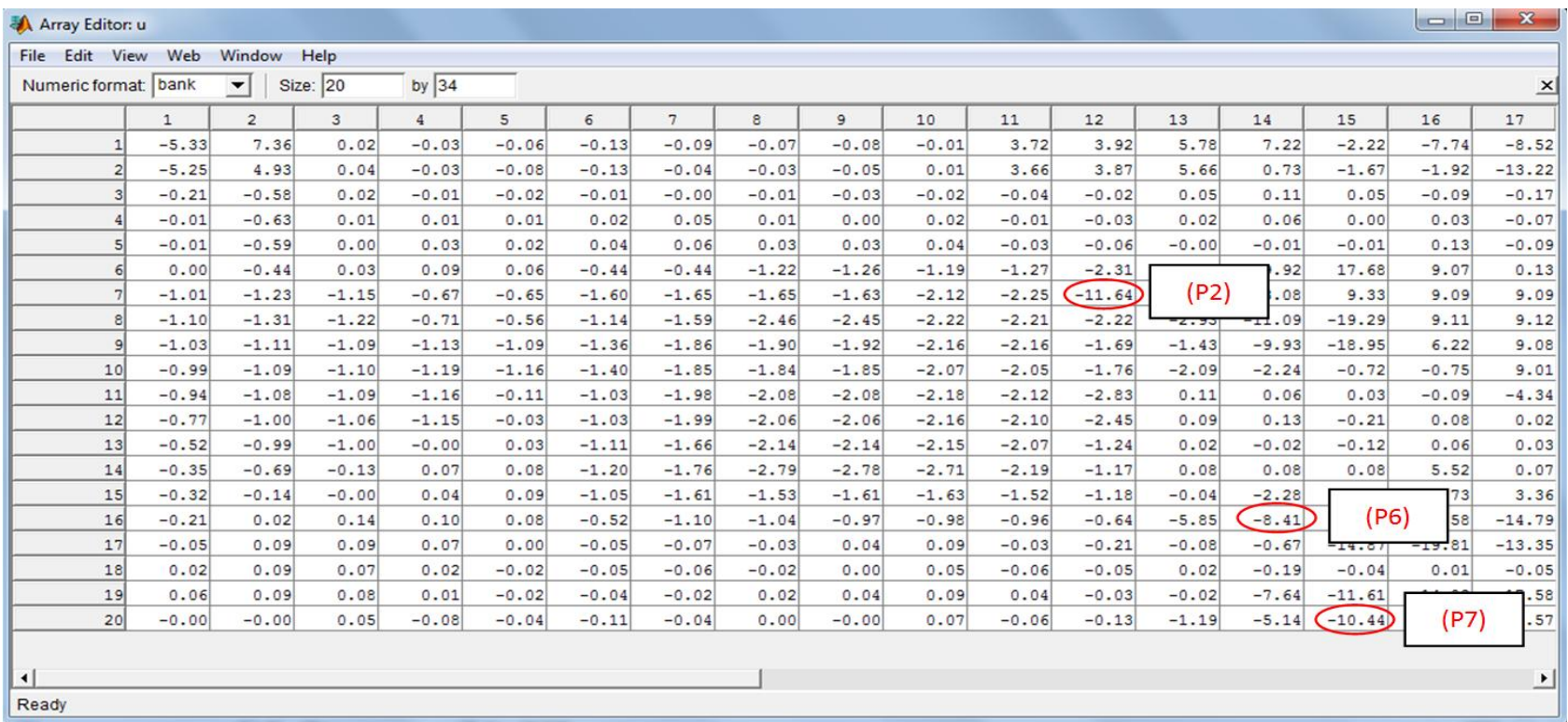

Fig. 6a: Velocity Generated from Fig. 5 in X-Direction

A Array Editor: u

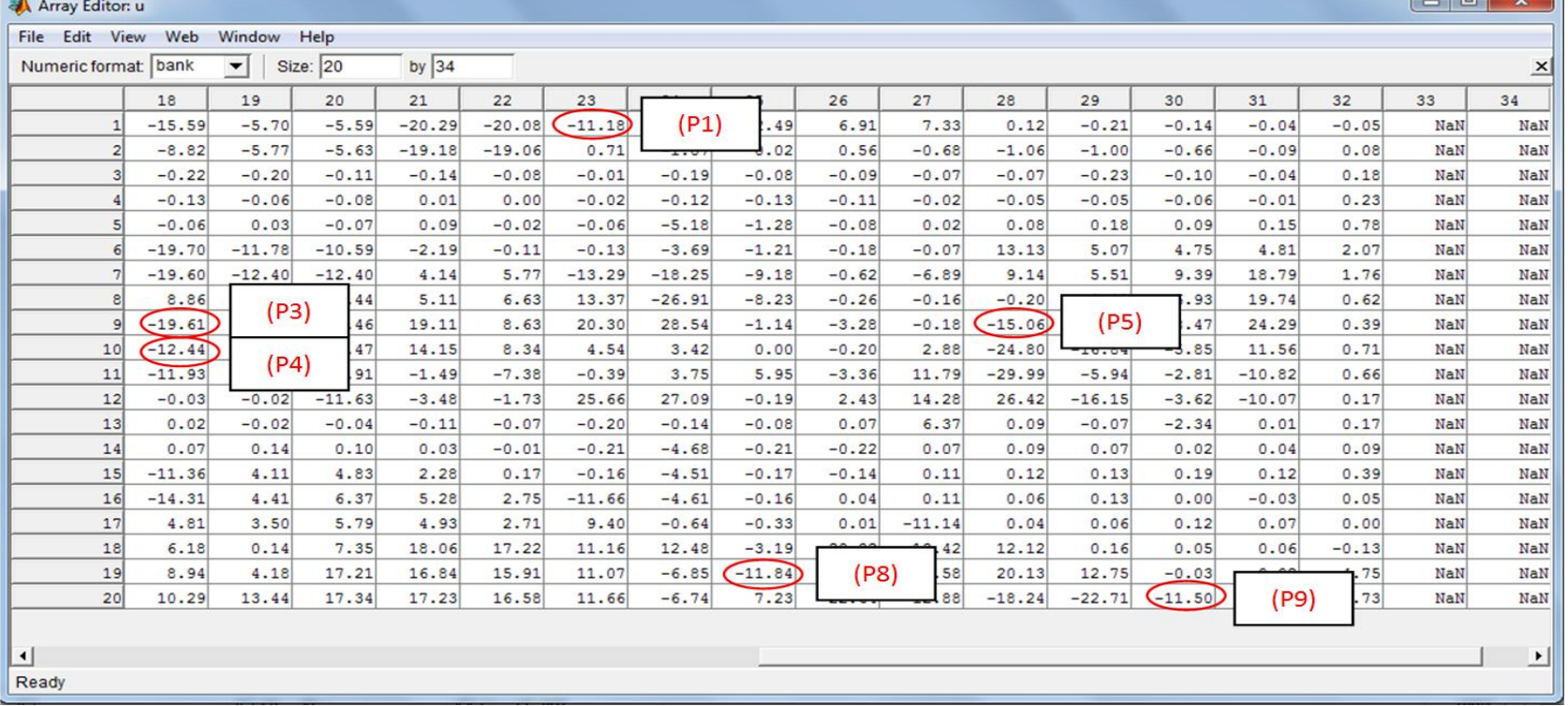

Fig. 6b: Velocity Generated from Fig. 5 in X-Direction (Cont)

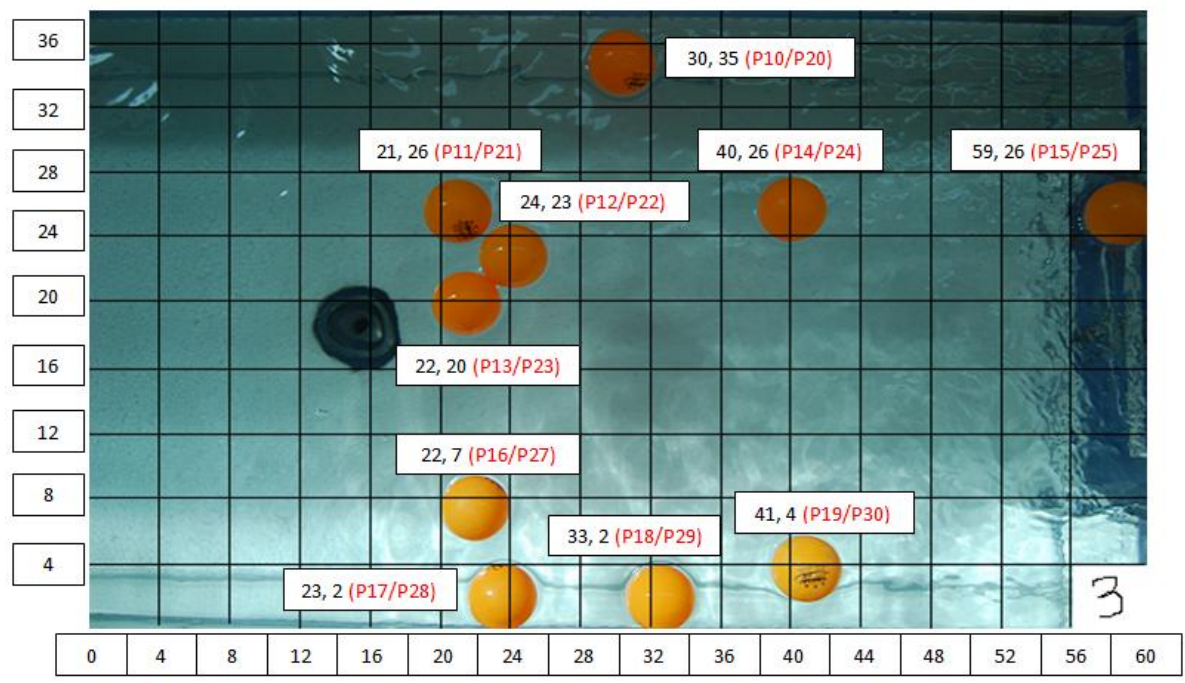

Fig. 7: Image Frame 3 with Ping Pong Ball IDs and Coordinates 


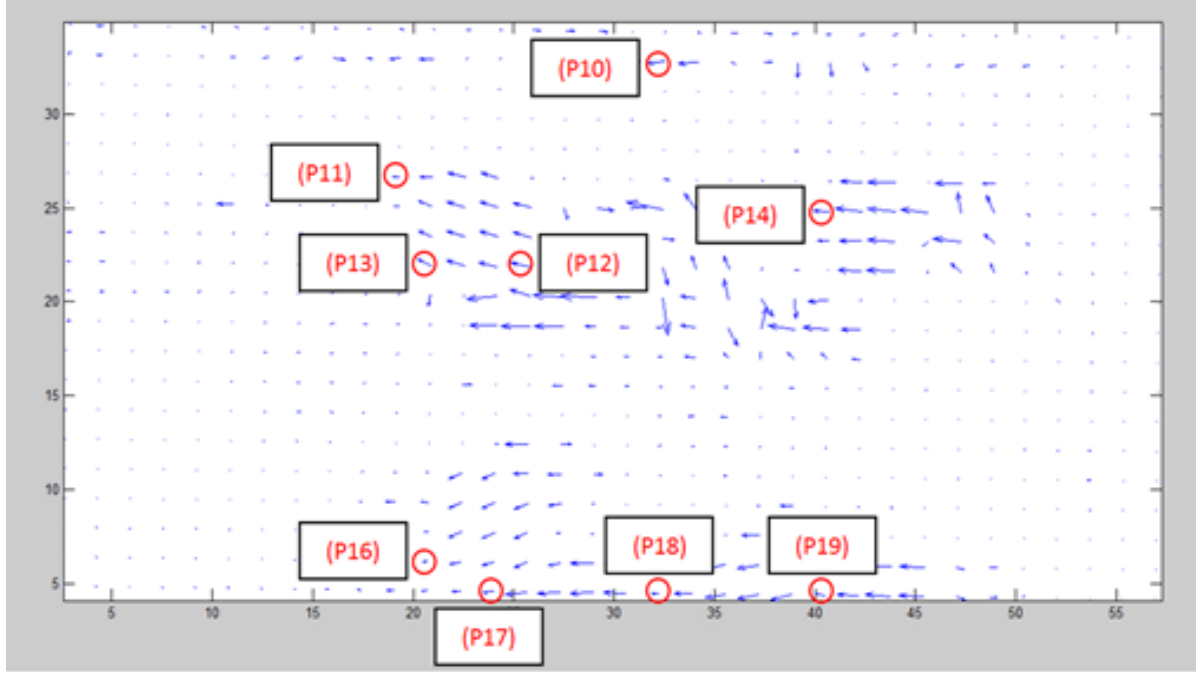

Fig.8: Velocity Vectors Generated for Frames 2 and 3

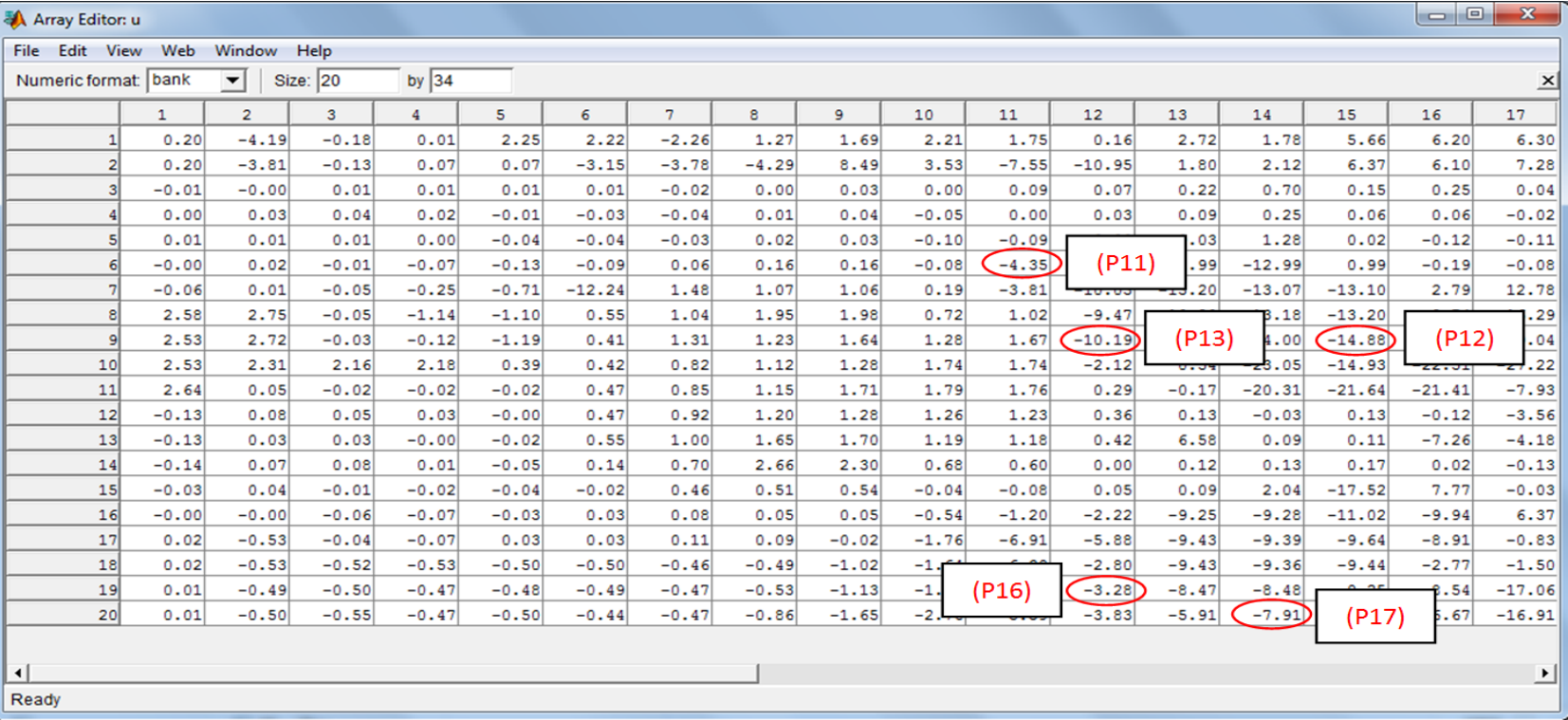

Fig. 9a: Velocity Generated for Fig.8 in X-Direction

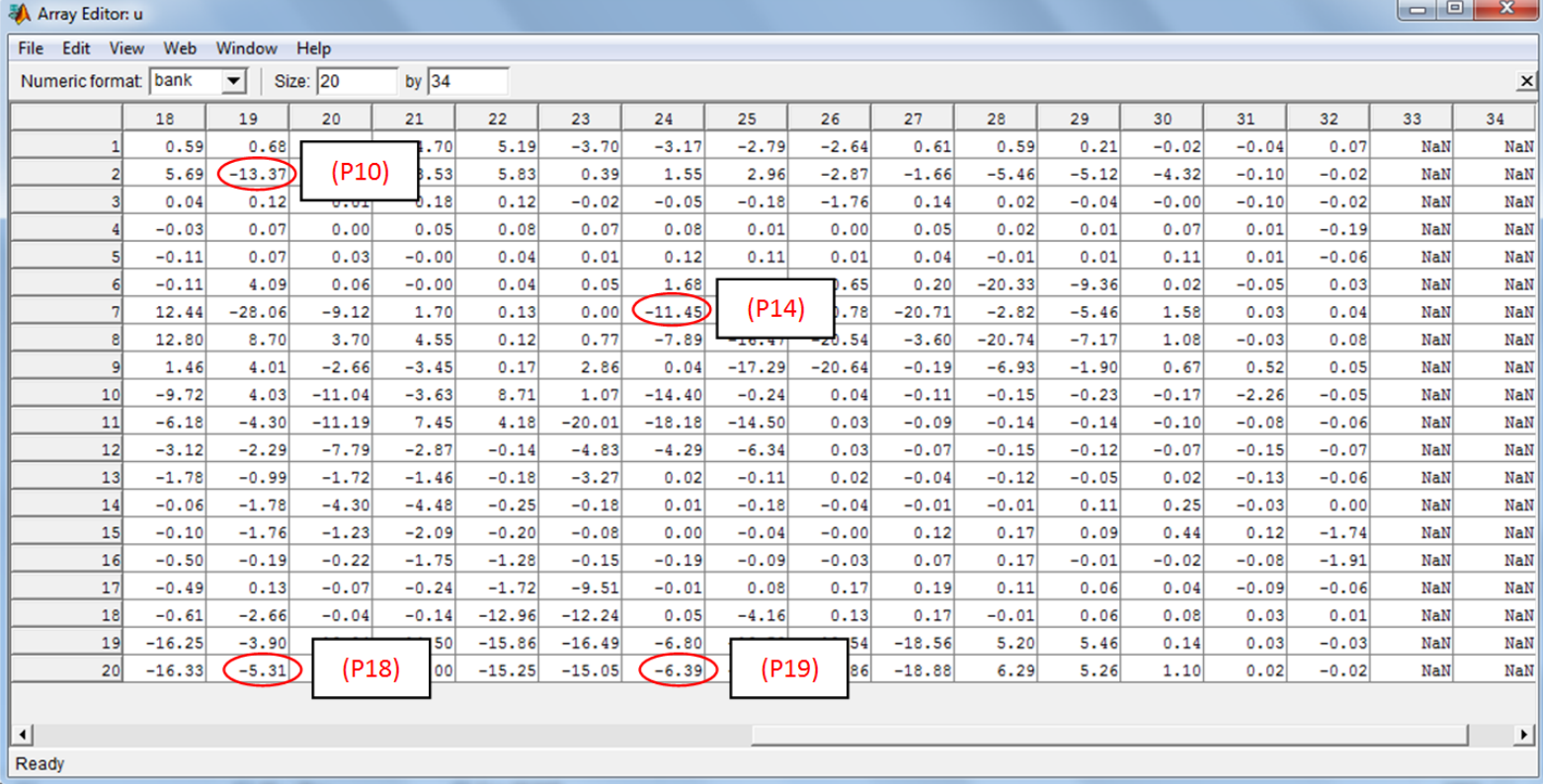

Fig. 9b: Velocity Generated from Fig 8 in X-Direction (Cont) 


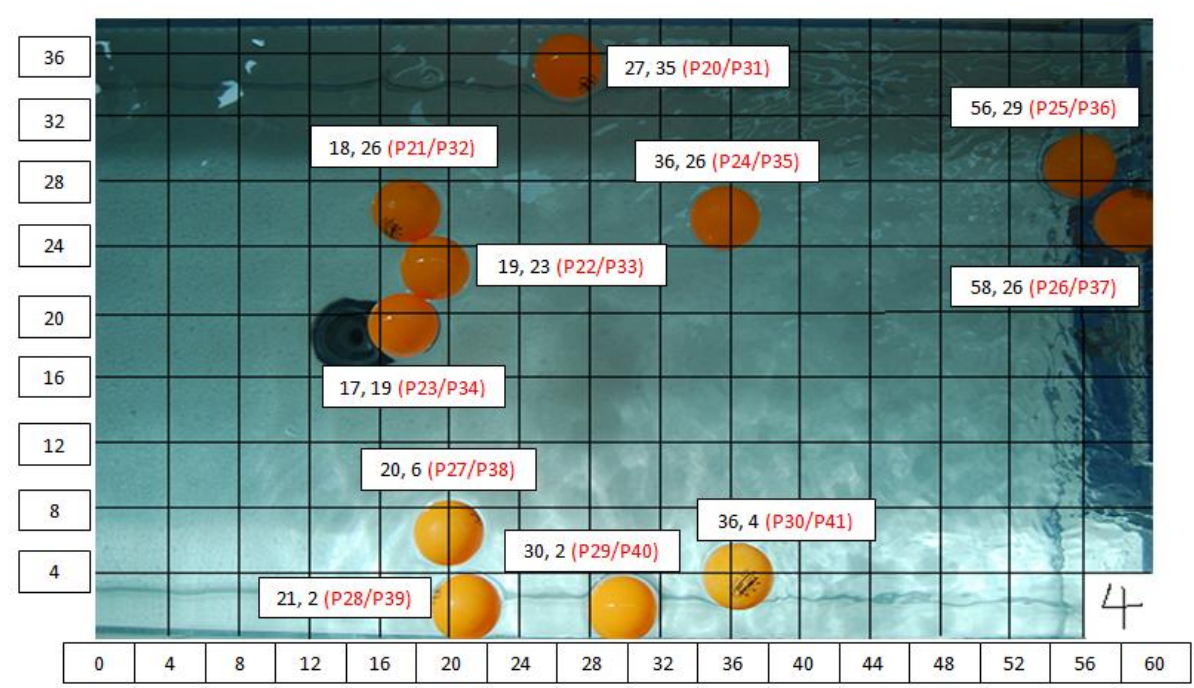

Fig.10: Image Frame 4 with Ping Pong Ball IDs andCoordinates

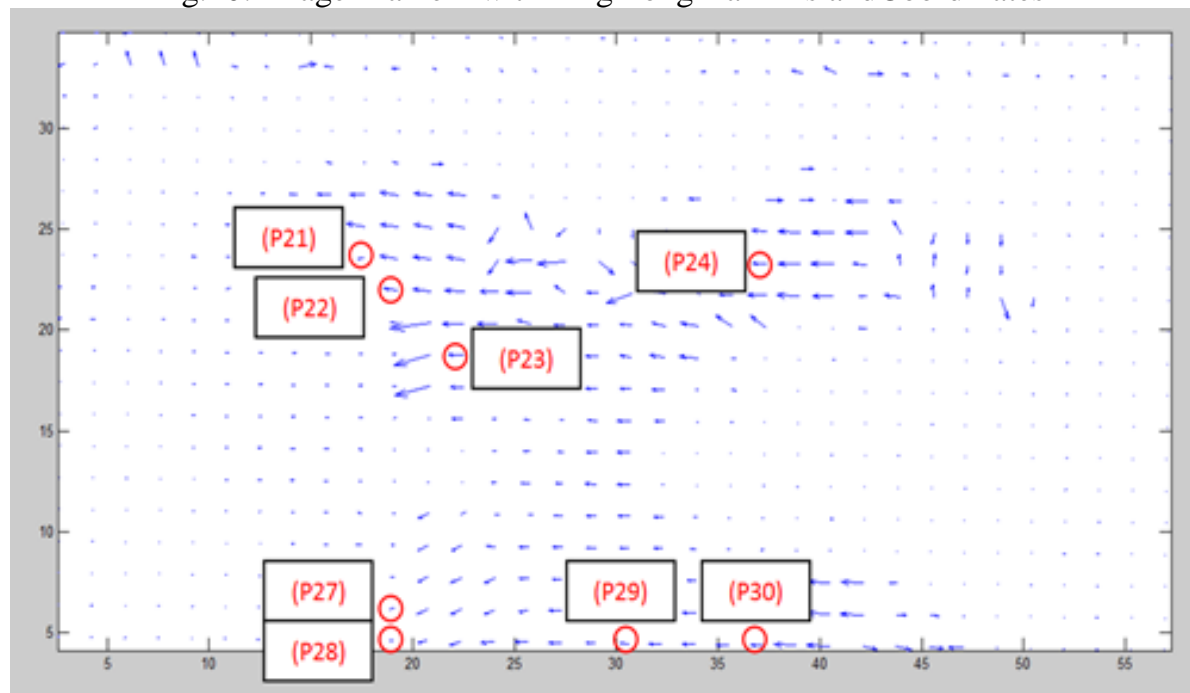

Fig. 11: Velocity Vectors Generated for Frames 3 and 4.

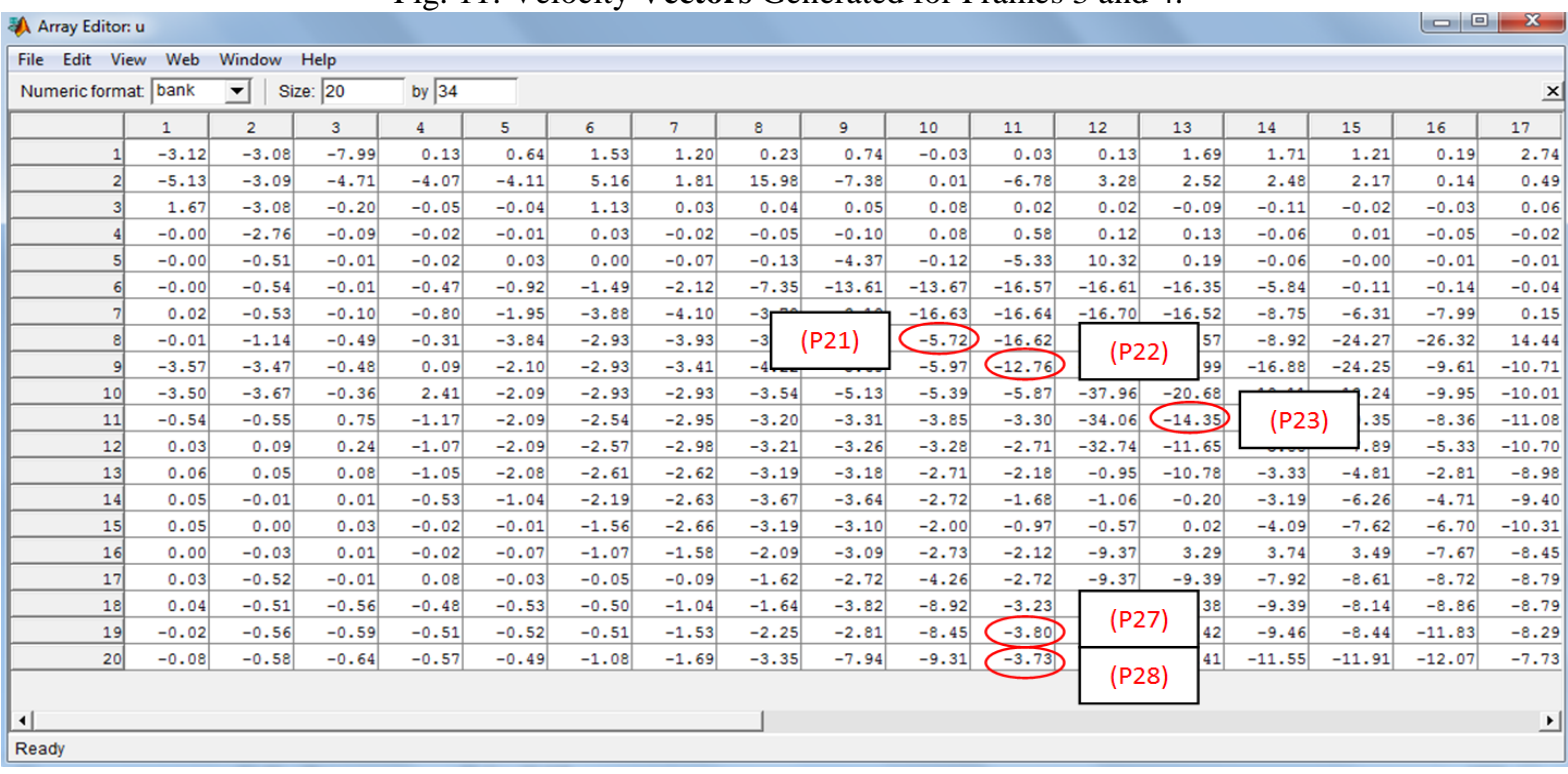

Fig.12a: Velocity Generated from Fig.11 in X-Direction 


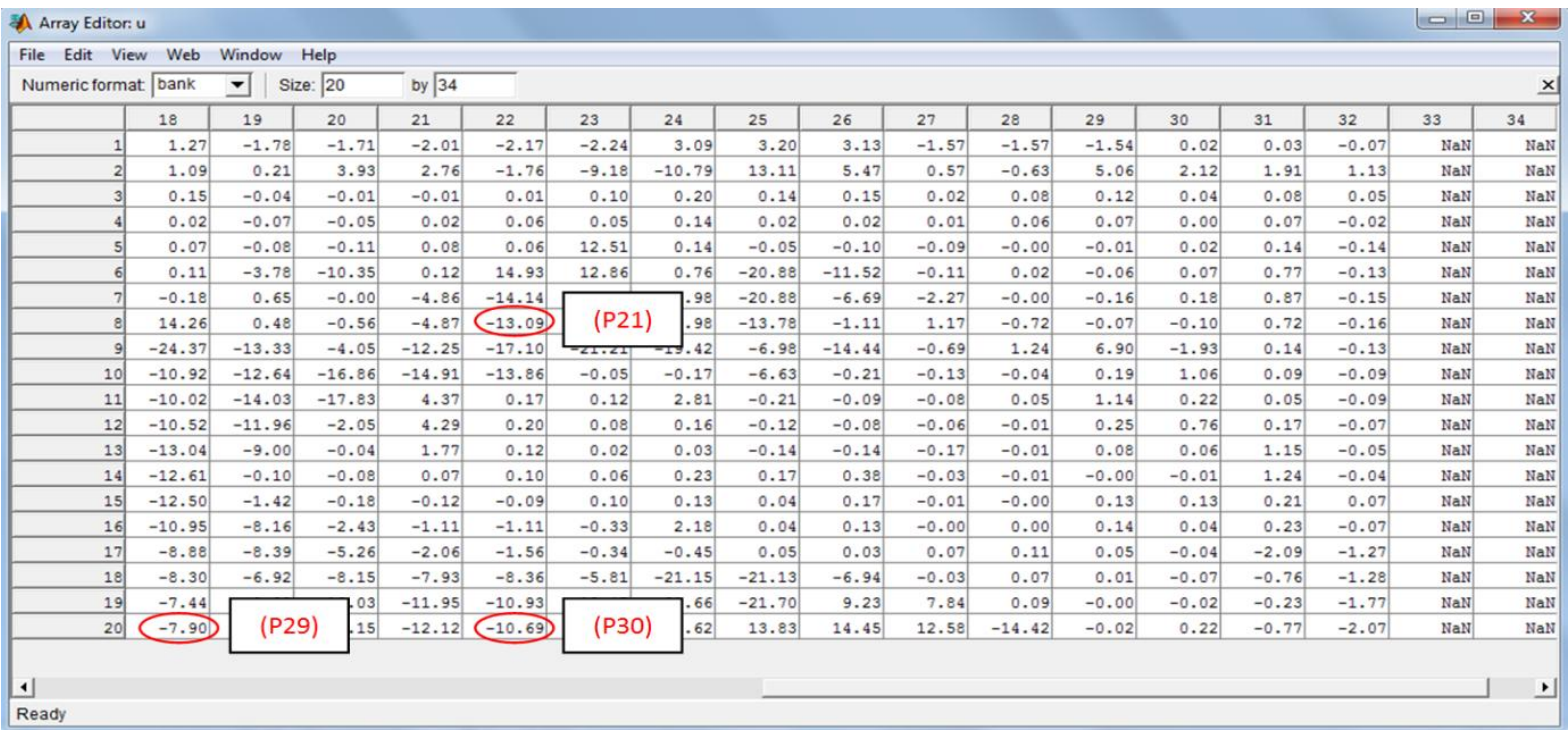

Fig. 12b: Velocity Generated from Fig. 11 in X-Direction (Cont)

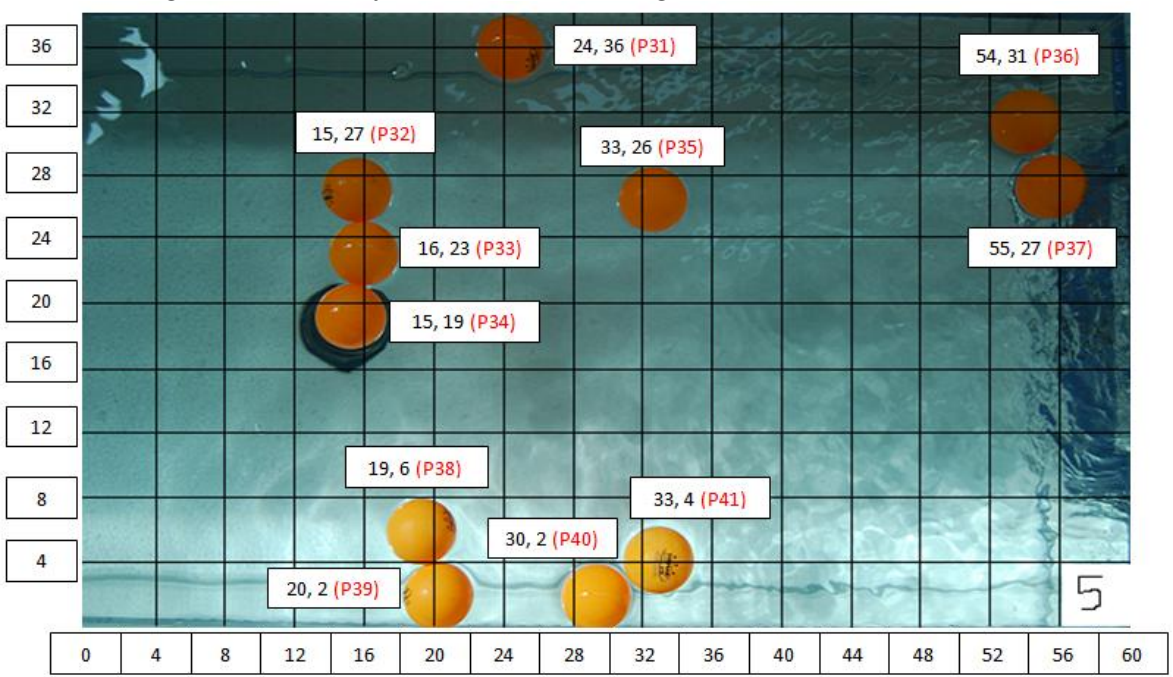

Fig.13: Image Frame 5 with Ping Pong Ball IDs and Coordinates

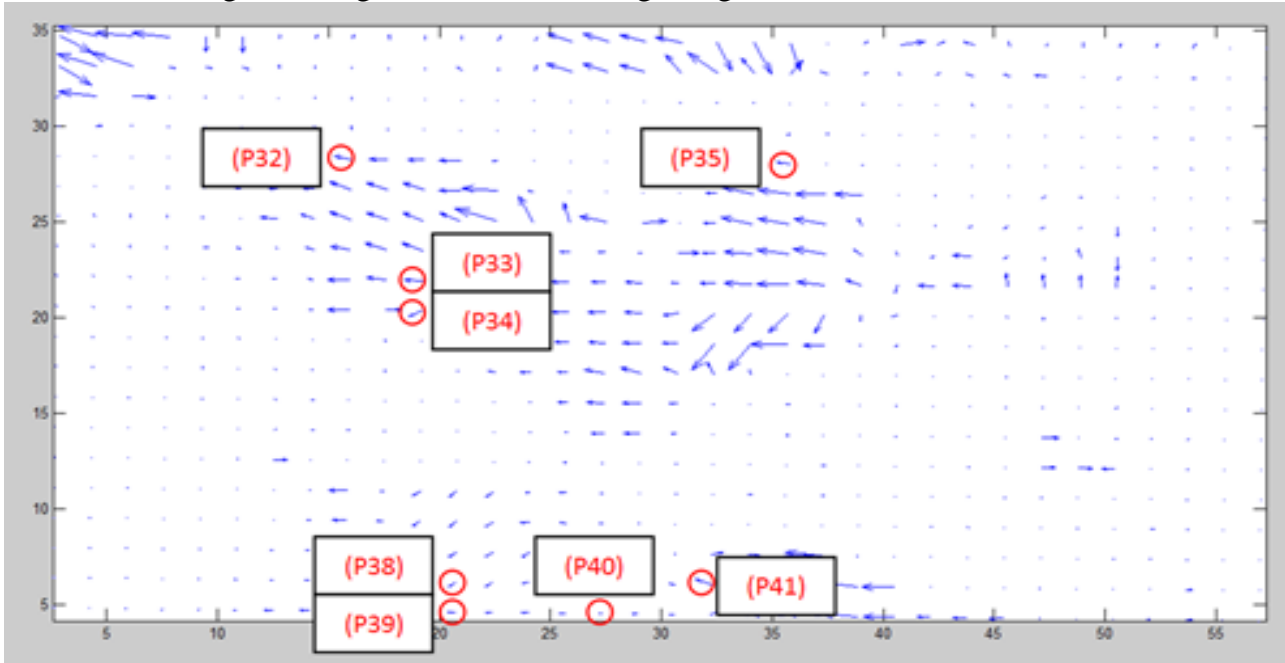

Fig. 14: Velocity Vectors Generated for Frames 4 and 5 


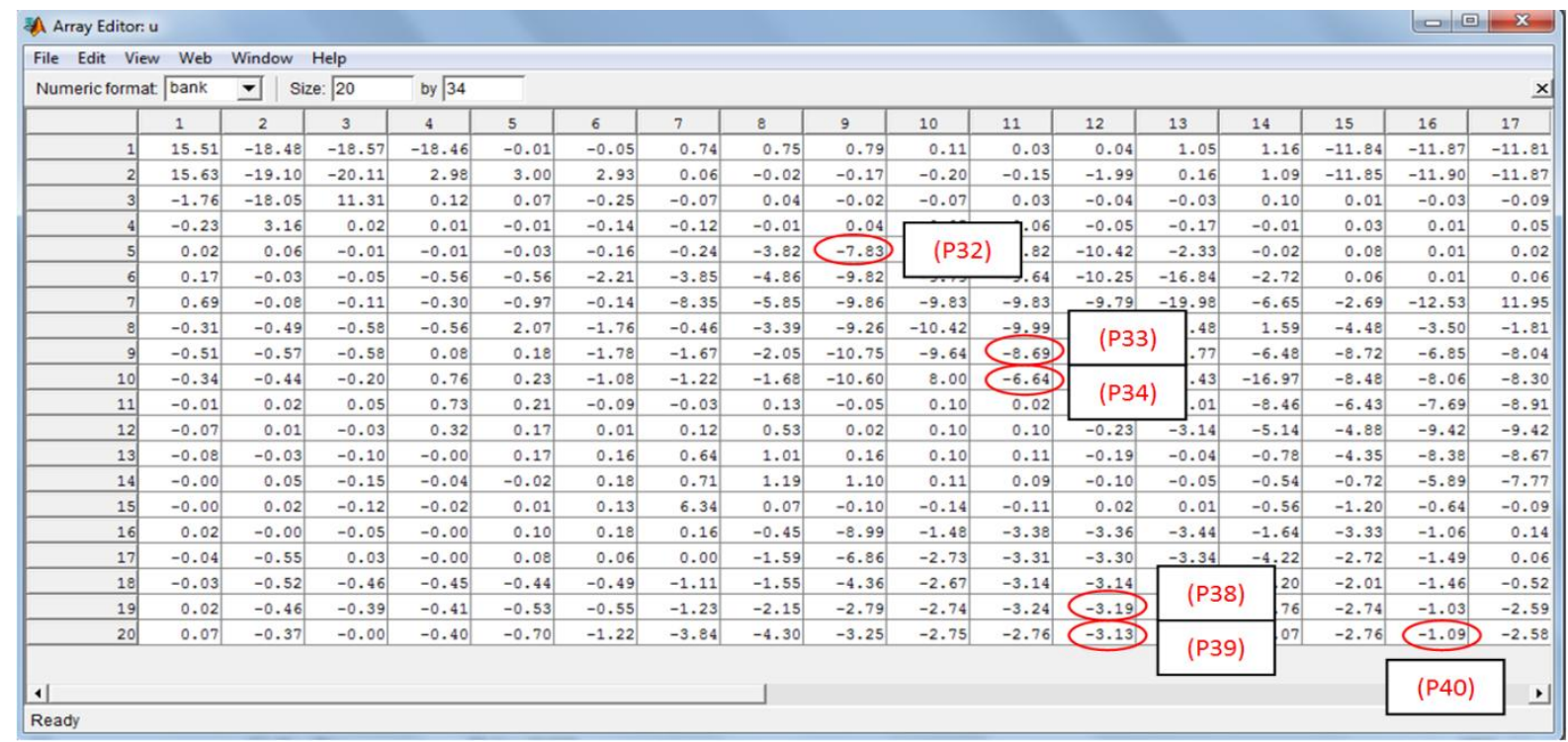

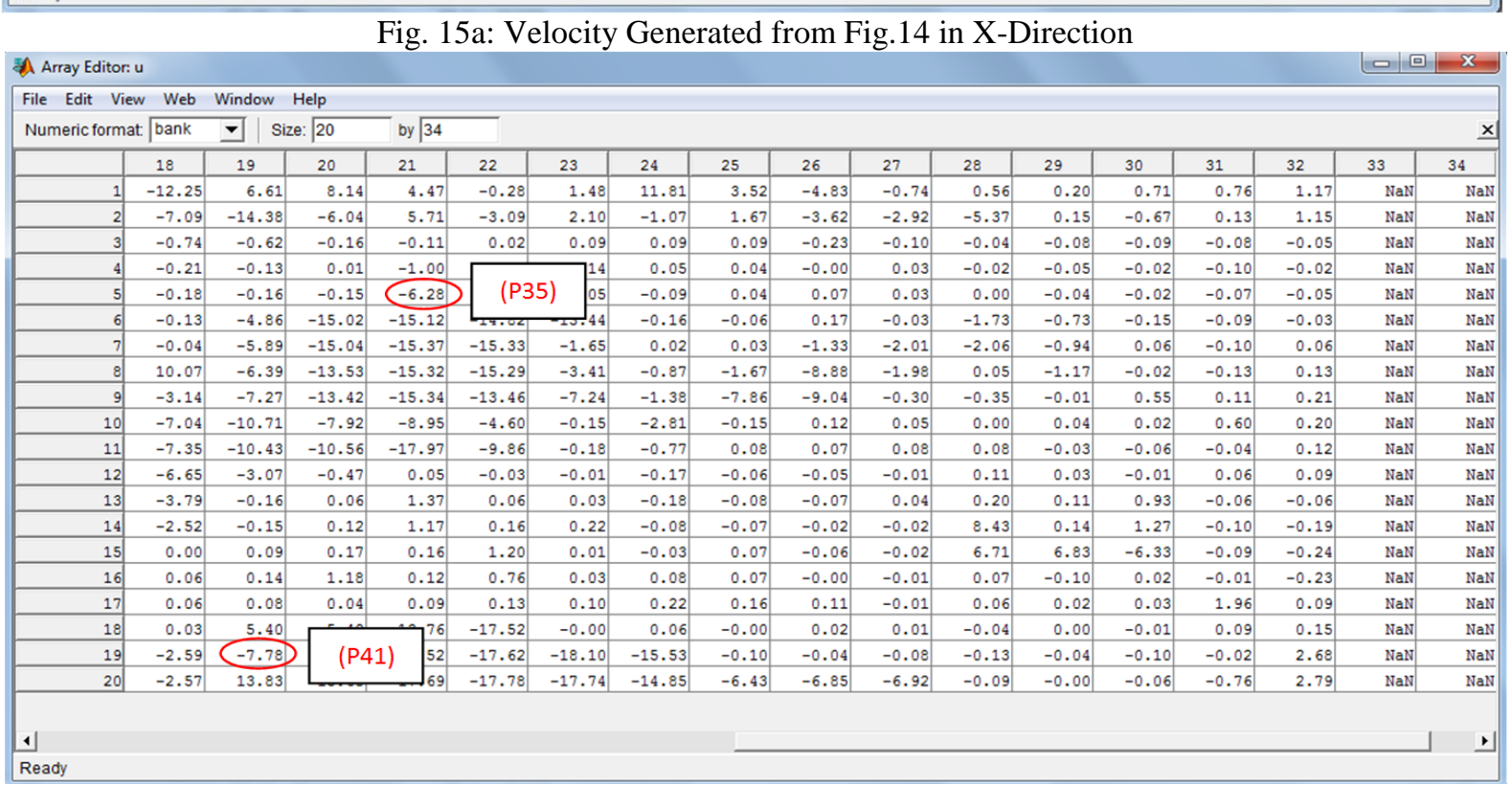

Fig. 15b: Velocity Generated from Fig.14 in X-Direction (Cont)

All the 41 ping pong balls were analyzed in this laboratory experiment and it was found the velocity results obtained from MatPIV is slightly different with actual velocity. Therefore, a correction factor as presented in Eq. 1 is employed to improve the results.

Correction Factor $=V_{\text {actual }} / V_{P I V}$ Eq. 1

Where $V_{\text {actual }}$ is Actual Velocity; $V_{P I V}$ is PIV Velocity

After analyzing 41 ping pong balls, it was found the average correction factor is 1.20 . Through the implementation of a standardized correction factor, the corrected $V_{P I V}$ was found to be in good agreement with the $V_{\text {actual }}$. There are a few factors that lead to inaccuracy of analyzed results. According to Prasad (2000), errors in PIV measurement might due to (1) Random error caused by noise in the image frames; (2) Bias error in the signal peak location and sub-pixel accuracy input; (3) Gradient error due to loss of correlation which is caused by rotation and deformation of the flow within the interrogation region; (4) Tracking error resulting from the inability of the tracer particle to follow the flow without slip; (5) Acceleration error induced by approximating the Eulerian flow velocity from the Lagrangian motion of the tracer particles. 


\section{Conclusion}

The study revealed that PIV has successfully determined the flow velocity in the Sedimentation Tank. Through the implementation of a standardized correction factor, the corrected PIV velocity were quite close to the acceptable range with the error margin of less than5\% which was deemed to be fairly accurate. The $V_{P I V}$ results showed to be in good agreement with the $V_{\text {actual }}$.

The findings from this research project proved that PIV fluid flow measurement technique is reliable, precise and accurate in measuring water flow velocity. This technique can be further improved for river gauging and monitoring and to detect the sediment inside the river.

Besides, it was also observed that shorter time interval between image frames would allow a more detailed and accurate PIV analysis. However, the drawback of using a normal digital camera or digital SLR camera in PIV analysis is the inability to capture the images of fast-moving tracer particles with dynamic movements. The countermeasure proposed would be using a high speed video camera that will capture 60 frames per second and would produce 12 times more images compared to the Nikon D40X digital SLR camera.

\section{References}

[1] Adrian, RJ.(1991). 'Particle-Imaging Techniques for Experimental Fluid Mechanics', University of Illinios, Urbana, Illinois, USA.

[2] Creutin, JD, Muste, M, Bradley, AA, Kim, SC \& Kruger, A.(2003). 'River Gauging using PIV Techniques: A Proof of Concept Experiment on the Iowa River', The University of Iowa, USA.

[3] Deng, Z, Richmond, MC, Guensch, GR\& Mueller, RP.(2004). 'Study of Fish Response using Particle Image Velocimetry and High-Speed, High-Resolution Imaging', U.S. Department of Energy, USA.

[4] Fujita, I, Muste, M, Kruger, A.(1998). 'Large-Scale Particle Image Velocimetry for Flow Analysis in Hydraulic Engineering Applications', Journal of Hydraulic Research, vol. 36, no. 3, pp. 397-414.

[5] Harpold, AA, Mostaghimi, S, Vlachos, PP, Brannan, K \& Dillaha, T. (2006). 'Stream Discharge Measurement using a Large-Scale Particle Image Velocimetry (LSPIV) Prototype', American Society of Agricultural and Biological Engineers, vol. 49, pp. 1791-1805.

[6] Jodeau, M, Hauet, A, Paquier, A, Le Coz, J\& Dramais, G.(2008). 'Application and Evaluation of LS-PIV Technique for the Monitoring of River Surface Velocities in High Flow Conditions', Flow Measurement and Instrumentation, vol. 19, pp. 117-127.

[7] Le Coz, J, Hauet, A, Pierrefeu, G, Dramais, G\& Camenen, B.(2010). 'Performance of Image-Based Velocimetry (LSPIV) Applied to Flash-Flood Discharge Measurements in Mediterranean Rivers', Journal of Hydrology, col. 394, pp. 42-52.

[8] Lowe, KT.(2006). 'Design and Application of a Novel Laser-Doppler Velocimetry for Turbulence Structural Measurements in Turbulent Boundary Layers', Virginia Polytechnic Institute and State University, Blacksburg, Virginia.

[9] Prasad, AK (2000). Particle Image Velocimetry, University of Delaware, New York, USA.

[10] Sveen, JK\& Cowen, EA (2004). 'Quantitative Imaging Techniques and Their Application to Wavy Flows', Cornell University, New York, USA. 